\title{
Ouvindo silêncios: Daniel Hogan, o mundo rural e a natureza
}

\author{
Flavia Maria Galizoni* \\ Eduardo Magalhães Ribeiro**
}

\begin{abstract}
A produção e as atitudes de Daniel Hogan (1942-2010) permanecem fundamentais para compreender as relações entre população e ambiente no rural brasileiro, especialmente no que diz respeito às grandes migrações, à urbanização acelerada e seus efeitos sobre o meio. Essas contribuições aparecem em estudos que pesquisaram silêncios - grandes lacunas que, até então, existiam na literatura. Assim, Hogan criou perspectivas analíticas inovadoras, que fortaleceram a capacidade de filtrar técnicas para orientar estudos.
\end{abstract}

Palavras-chave: População rural. Ambiente. Migrações. Daniel Hogan.

\footnotetext{
* Universidade Federal de Minas Gerais (UFMG), Montes Claros-MG, Brasil (flaviagalizoni@yahoo.com.br; https://orcid. org/0000-0002-7567-1269).

** Universidade Federal de Minas Gerais (UFMG), Montes Claros-MG, Brasil (eduardoribeiromacuni@gmail.com; https:// orcid.org/0000-0002-3822-9084).
} 


\section{Introdução}

João Guimarães Rosa, em “Corpo de Baile - Uma estória de amor (Festa de Manuelzão)", narra a saga do vaqueiro Manuelzão. 0 vaqueiro havia construído sua casa perto de uma nascente para sempre ter água fresca à disposição. Certa noite acordou com um silêncio não com um barulho, mas com um silêncio que o angustiou. E ele sentiu, antes mesmo de ver, que a nascente secara, parara de correr e "barulhar": "o riacho soluço se estancara, sem resto, e talvez para sempre".

Daniel Hogan foi um raro pesquisador que, como o vaqueiro Manuelzão, sabia ouvir os silêncios. Esta qualidade marcou sua produção e contribuições deixadas para compreender as relações entre população, ambiente e migrações no rural brasileiro. Essas contribuições aparecem na proposição de temas de estudos que abriram perspectivas analíticas inovadoras e na capacidade que Hogan teve de selecionar as técnicas para orientar estudos.

\section{Pesquisador $^{1}$}

Os estudos sobre a migração da população rural têm sido marca constante da produção sobre algumas regiões brasileiras, como o norte e nordeste de Minas Gerais. De lá costumavam sair, ano a ano, milhares de agricultores e agricultoras que refaziam o trajeto destas até outras regiões em busca de empregos e trabalhos temporários, que combinavam com atividades agrícolas e labores rurais, compondo estratégias familiares de trabalho e produção. A migração, neste contexto, não podia ser entendida em separado da relação com a terra e os recursos, nem fora das relações familiares. Essa migração não decorria de atitude individual, não se associava apenas a questões conjunturais ou climáticas; na verdade, se relacionava com fenômenos estruturais e simbólicos: escassez de terra, exaustão do ambiente, amealhamento de recursos, ritos de passagem, conhecimento de mundo.

A mobilidade sempre fez parte da trajetória da população rural brasileira, principalmente de agricultores familiares. Antônio Cândido, nos anos 1950, abordou este tema em Os parceiros do rio Bonito, analisando suas consequências para os agricultores e suas famílias. 0 autor mostrou como a mobilidade em busca de novas terras era estrutural na "sociedade caipira" por ele estudada. A mobilidade era animada pela agricultura itinerante, motor da ocupação da terra. Cândido (1975) apontou o ambiente como fator, ao mesmo tempo, dadivoso e limitante para a organização da produção desses agricultores familiares. Quando, no quadro das técnicas agrícolas dos lavradores, um determinado meio se exauria, o agricultor corrigia a situação pela mobilidade, que permitia recriar o meio e as condições desejadas de produção, restabelecendo as condições costumeiras da relação da população com o ambiente. Para ele, a mobilidade apresentava dupla face: instabilizava

\footnotetext{
${ }^{1}$ Trechos dessa primeira seção foram parcialmente publicados, em versões preliminares, em artigos dos autores em Anais do XI Encontro da Associação Brasileira de Estudos Populacionais e em Anais do IX Seminário sobre a Economia Mineira.
} 
por um lado, ao propiciar a dispersão espacial; reparava por outro, ao recriar as condições de acesso à fertilidade das terras, necessárias para a reprodução da família. Estudando uma sociedade em transformação, num período de esgotamento do livre acesso às terras, o autor demonstrou que a mobilidade no espaço era fundamental para a persistência da organização social, que era vinculada ao sistema de produção.

Maria Isaura Pereira de Queiroz (1973), ao estudar bairros rurais paulistas, concluiu que não apenas as famílias rurais eram móveis no espaço, mas também sua unidade social ampliada - o "bairro" - participava desta mobilidade. Baseada em historiadores do século XIX, a autora afirmou que o bairro rural não está fixamente implantado no espaço, mas, ao contrário, é “uma unidade móvel no espaço geográfico brasileiro”. A técnica agrícola utilizada - a agricultura itinerante - impunha para esses agricultores um deslocamento constante. Contrapondo-se à dispersão geográfica, os laços de parentesco eram fios que restauravam a unidade das famílias, unificando-as em espaços sociais e simbólicos, independentemente do distanciamento espacial. Espaços geográficos, sociais e sobrenaturais formavam um todo inseparável, mas ao mesmo tempo ambíguo, pois o espaço era vasto e difuso, porém percebido como um recorte produzido pelos instrumentos culturais do grupo em questão: as relações de vizinhança e parentesco. Queiroz analisou a adaptação dos habitantes do meio rural às grandes cidades, perguntando se a mudança para a cidade outro espaço também difuso, vasto e inesgotável - não seria, talvez, uma busca, em novo plano, da dimensão espacial rural perdida com o rompimento de relações "tradicionais" de acesso à terra e aos recursos naturais.

Carlos Castaldi (1957), em A aparição do demônio de Catulé, ensaio sobre o surto messiânico dos lavradores de Malacacheta, em Minas Gerais, localizou as rupturas nas relações entre lavrador e ambiente - causadas por formas de apropriação que limitavam o acesso à terra e à mata e, consequentemente, à possibilidade de mobilidade territorial por estes lavradores - como fator explicativo para o movimento migratório. Viajavam para conseguir meios para adquirir terras, que anteriormente posseavam; e também para fazer frente às necessidades de dinheiro que surgiam em decorrência do processo de unificação das regiões econômicas e criação de um mercado nacional de bens.

Cândido, Queiroz e Castaldi analisaram populações rurais em momentos em que a sociedade brasileira passou por processo de urbanização que redefiniu profundamente os espaços sociais e as relações entre rural e urbano. Os autores observaram que os desajustes nas famílias de agricultores, diante das mudanças de formas de apropriação das terras, conjugadas ao processo de urbanização, se resolveram cada vez mais pelo abandono das atividades agrícolas, pela migração urbana e - segundo Cândido - pela passagem a outro universo cultural. Esses estudiosos afirmaram que a urbanização propiciou aos lavradores a possibilidade de encontrar, em um plano diferente, os espaços necessários à mobilidade da família: a cidade se apresentou como sucessora do espaço e ambiente rural, como forma de se desvencilhar de sujeições de um mundo agrário mandonista. Eles assinalaram os momentos em que a mobilidade da população rural se transforma em migração: quando se 
esgotava a possibilidade de deslocamento pelo espaço devido ao fechamento de fronteiras agrícolas ou à impossibilidade de acesso a novas terras.

Estava posta, assim, a base para compreender parte da grande transformação do espaço nacional que aconteceu em decorrência das migrações dos anos 1960 e 1970.

Até as décadas de 1950 e 1960, a urbanização permanente ou temporária de trabalhadores rurais recebia uma avaliação altamente positiva por parte do migrante, da sociedade urbana e dos estudiosos. E assim acontecia do ponto de vista tanto da região de origem quanto da de destino. Dos anos 1970 em diante, a concepção de migração existente na sociedade foi se transformando. Se, até então, o fluxo populacional era percebido como ascensão social, importante para o desenvolvimento e urbanização da sociedade brasileira, a partir desta década migração passou a ser interpretada como ruptura: de vida, trabalho, cultura e família, mudança imposta à população rural que esvaziava o campo e enchia a cidade. Autores como Lopes (1973) e Camargo et al. (1976) e publicações de pastorais religiosas ilustram este viés de análise.

Refletindo sobre as indagações que moviam as investigações sociológicas deste período, Daniel Hogan, em seu livro Cidades: usos e abusos (1978), mostrou que havia aí uma questão central: como uma população de origem rural e prática agrícola recente se adaptava ao meio urbano? Que novo urbano era esse que nascia do impacto de migrações tão volumosas? Foi assim que Daniel Hogan conseguiu colocar uma questão pioneira, pois investigava os mecanismos de ruptura e continuidade em dois meios - rural e urbano - que então eram considerados opostos, não apenas no sentido físico-geográfico, mas principalmente no cultural, pois um seria a materialização do atraso, enquanto o outro seria a configuração da modernização que poderia ser possível na sociedade brasileira.

Nesse sentido, os estudos de Hogan indicaram que a migração é uma reconstrução constante do equipamento cultural de indivíduos e comunidades, constituindo mesmo em tradições migratórias comunitárias, que instrumentalizaram o migrante com conhecimento mínimo do ambiente para o qual se dirigia. Haveria um aspecto grupal e familiar da migração, que não necessariamente dissolvia abruptamente laços sociais, mas se apresentava como movimentação no universo social, como tentativa de repor a mobilidade social. $E$ então, espaços sociais e espaços físicos - ou seja ambientes - teriam que ser submetidos aos mesmos crivos para que a dinâmica das migrações pudesse ser compreendida (HOGAN, 1978, 1991, 1996).

A leitura feita por Hogan fortaleceu, para outros autores, a percepção de que a comunidade de origem oferecia um arcabouço cultural que filtrava as mudanças pelas quais passavam os migrantes. As novas relações eram re-formuladas nos termos do universo comunitário e passavam por adaptação às novas formas de vida: os locais de destino de migrações e os tipos de trabalho desenvolvidos eram instrumentos para compreender a história migratória de um determinado grupo social, e poderiam ser lidos como permanências, oportunidades e, no limite, recursos mobilizáveis. A migração re-produzia a formação de uma antiga teia, baseada em relações de parentesco que uniam seções rurais e urbanas 
das mesmas famílias e comunidades. A localidade de origem do camponês migrante teria quase sempre uma correspondência com o local de destino. Como, geralmente, a saída refletia uma trajetória familiar, haveria destinos muito variados que se combinavam, revelando estratégias ao mesmo tempo familiares e comunitárias (HOGAN, 1978, 1991). ${ }^{2}$

Se a mobilidade da população rural e sua relação com o meio esteveram fortemente presentes nas análises das ciências sociais sobre população rural até a década de 1960, “as grandes migrações" que ocorreram no país, principalmente nos anos 1970, nublaram este aspecto. Em parte, porque o grande número de pessoas que afluíram do rural para os centros urbanos colocou novas questões e outros temas, e a centralidade da relação homem-ambiente ou sociedade-natureza desapareceu como parte obrigatória da interpretação do processo de adaptação. 0 peso demográfico dos deslocamentos humanos sem precedentes, a industrialização dos tempos do "milagre" e a emergência do "boia fria" no campo monopolizaram as atenções dos estudiosos.

A urbanização-industrialização, como dualidade complementar, teve, sem dúvida, um impacto sobre aqueles que chegaram à cidade nas últimas décadas, e era justificada a atenção dos estudiosos. Mas estes deixaram de lado ambiente e recursos para pautar os estudos deste período pela marginalidade social, êxodo, inserção ocupacional e adaptação do migrante na cidade. A dinâmica relação entre um grupo social e o meio onde ele está inserido empalideceu nas reflexões sobre um migrante massificado. Mas, certamente, as continuidades e descontinuidades referentes aos recursos naturais e a relação dos migrantes com o meio eram fatores importantes no processo de adaptação, sendo nesse contexto que a produção de Daniel Hogan reavivou de forma significativa a análise da relação entre população rural e ambiente. Mas ele inovou ao fazer isso a partir de uma nova perspectiva: a da cidade.

Em seu texto “População, pobreza e poluição em Cubatão”, Hogan (1996) introduziu como preocupação de pesquisa a percepção da população migrante a respeito do ambiente no urbano. A necessidade de investigar essa questão se consolidou quando o estudioso observou que o tema poluição, que comovia a sociedade e a comunidade científica, não encontrava eco entre os moradores de Cubatão. Por isso era importante captar o olhar da população e desvendar porque este tema, tão urgente na visão da sociedade envolvente, não tocava a população local. A indagação transversal a todo o estudo é: "quem pagou (e paga) o preço da poluição?" Para responder a esta pergunta, Hogan estruturou uma metodologia que combinava elementos quantitativos com informações qualitativas. Primeiro ele analisou a dinâmica demográfica que responde pelo perfil dos habitantes e sua relação com ocupação do espaço. Conhecido o perfil - migrantes pendulares, em sua maioria homens solteiros, negros ou pardos, com baixa escolaridade, nordestinos, que ficavam pouco tempo em Cubatão -, Hogan realizou uma análise deste perfil articulada com o padrão de assentamento seletivo de Cubatão, marcado ainda pela geografia específica da cidade.

\footnotetext{
$\overline{2}$ Nesse sentido ver também o estudo clássico de Eunice Durham (1973).
} 
O autor concluiu que, mesmo na cidade intitulada na época como a mais poluída do mundo, "a poluição é socialmente dirigida a determinados segmentos populacionais" - a alguns segmentos cabia uma parcela maior do ônus. E esta foi uma revelação extremamente importante, pois mostrou como elementos relacionados a projetos de desenvolvimento econômico-industrial, seus impactos e consequências ambientais combinadas com dinâmicas demográficas criaram situações de degradações ambientais e assentamentos perversos para segmentos da população, que, afinal, pagaram a conta.

Mas como estes segmentos populacionais percebiam tal impacto, espaço e ambiente? Para captar a percepção ambiental, Hogan utilizou entrevistas exploratórias em alguns bairros. Organizou a pesquisa de forma a permitir que a "população falasse por conta própria" sobre os temas saúde e migração. 0 importante, afirmou o autor, era que ficasse bem claro quando a informação era "oferecida" espontaneamente pelo entrevistado e quando era "extraída" pelos pesquisadores. Na circunstância pesquisada, fazer com que a população de migrantes falasse era algo muito delicado, pois os dados mostravam uma população que estava literalmente acuada pelo espaço, pela opinião pública, pela poluição. Ao ser abordada, por exemplo, a polêmica sobre ocorrência de defeitos congênitos, tema extremamente sensível, algumas pessoas atribuíam a incidência a desvios individuais de conduta e não associavam à exposição a agentes nocivos, dizendo: "é fruto das safadezas das mulheres. Elas dormem com todo mundo, aí o filho nasce com braço de um, perna de outro" (HOGAN, 1996, p. 123).

Foi nessa circunstância tensa que Daniel Hogan escutou o silêncio destes migrantes. Silêncio eloquente, que falava de seu lugar, de um lugar possível para eles. Falava de uma "situação de severa degradação ambiental" e seus efeitos, mas, principalmente, narrava como esta população sentia e reproduzia o tanto de ambiguidade que havia nesta situação e, dentro das suas margens de atuação, construía formas de lidar com o lugar, o ambiente e de "aceitar" a poluição. Esta perspectiva delicada de articular a análise macro com a interpretação minuciosa da forma como os sujeitos sociais vivem uma situação e refletem sobre ela é uma grande lição.

Hogan mostrou que a inserção do migrante rural no meio urbano podia ser então captada por um novo ângulo, valorizando o componente ambiental (HOGAN, 1991, 1998, $2000,2005,2007)$. Esta inserção mostrava riscos e vulnerabilidades nas construções de modos de vida e, consequentemente, de análises. Foi dessa forma que as pesquisas de Hogan acrescentaram, aos estudos urbanos, o mesmo valor heurístico e norteador que os trabalhos de Cândido, Queiróz e Castaldi acrescentaram aos estudos sobre o rural. Os recursos naturais não desapareciam na sociedade urbana; ao contrário, permaneciam muito vivos e, da mesma forma que os regimes de apropriação e uso determinaram um destino peregrino aos pobres do campo, a máquina do mundo urbano também lhes soubera impor o pior, como uma fatalidade. A distribuição profundamente desigual das consequências nocivas da poluição revelou a presença silenciosa da natureza, e se pode perceber que havia natureza na cidade, pois, até então, sequer se considerava a cidade parte do ambiente. 
O estudo de caso de Cubatão foi emblemático nas investigações conduzidas por Hogan sobre as relações entre dinâmicas demográficas e ambientes, indicando que havia elementos que complexificavam a equação malthusiana da pressão dos números sobre recursos. Era preciso ir além, aprofundar a investigação entre população e ambiente; entre população, ambiente e desenvolvimento; entre pressão demográfica e escassez de recursos naturais. Hogan trouxe novos olhares e sintetizou temas para reler esta equação.

\section{Orientador}

Hogan também trouxe novas perspectivas de pesquisas, fazendo isso, principalmente, de duas formas.

Primeira: conseguiu sempre fazer uma grande síntese do "estado da arte" da reflexão e evolução teórica da temática população e ambiente. Ele realizou extensas e precisas sínteses críticas de como determinados temas eram importantes para compreender essa relação. Em seus estudos encontram-se preciosas revisões sobre população e meio, sobre diferentes abordagens da relação entre crescimento demográfico e degradação de recursos, capacidade de suporte, migrações e padrões de assentamento, vulnerabilidade, fatores ambientais e distribuição populacional. Hogan propôs abordagens holísticas que, mesmo tendo como eixo central a demografia, transbordaram para diversas áreas do conhecimento: foram sempre análises transdisciplinares e, por isso, também fontes de influência para pesquisadores de diversas formações.

E Hogan sintetizou criticamente percursos intelectuais (e seus autores) que buscaram analisar a pressão demográfica como um fator agravante em problemas ambientais, mas não como determinantes. Nesse sentido, ele colocou para a demografia temas como desigualdade social e iniquidade no acesso a recursos e concentração de terras. Esta politização da pressão de números sobre recursos foi extremamente importante, pois requalificou 0 debate simplista sobre tamanho da população e escassez de recursos naturais. A pressão sobre recursos poderia, inclusive, trazer resultados positivos como aspecto importante para o desenvolvimento técnico de uma sociedade, mas também poderia agudizar a concentração na partilha de recursos e ter efeitos nefastos sobre a manutenção dos próprios recursos, como no exemplo da pesca da anchova peruana, utilizado por Hogan para pioneiramente criticar Hardin e sua "tragédia dos comuns".

Para Hogan existiam reciprocidades entre modelos de desenvolvimento, usos de recursos naturais e processos de distribuição populacional. Ao refletir sobre exemplos empíricos de escassez ou degradação de recurso e sua relação com o conceito de pressão demográfica, não só sintetizou o "estado da arte" da discussão teórica, como também indicou que era necessário decompor este conceito teórico, pois os exemplos indicavam que: "Primeiro, o dano provocado por números é sempre condicionado pela tecnologia empregada; segundo, direcionado pela estrutura social” (HOGAN, 1991, p. 61). Assim, reafirmou em seus estudos que não são as conjunturas ambientais e/ou climáticas que 
influíam em processos de mobilidade populacional, mas sim aspectos estruturais de determinada sociedade que definiam os reordenamentos populacionais.

Hogan constatou que o desenvolvimentismo, que marcou os anos de crescimento econômico acelerado no Brasil, não deixou muito espaço para tratar questões ambientais e sociais; ao contrário, estas questões foram pensadas como entraves. Em relação ao rural brasileiro isso se tornou particularmente mais concreto nos últimos 40 anos do século $\mathrm{XX}$, depois que programas de desenvolvimento e modernização rural fundamentados na revolução verde - baseada na especialização produtiva, com uso contínuo de adubo, trator, veneno e muita água - disseminaram no campo processos intensivos de produção. Essa “modernização da agricultura” provocou efeitos de concentração de terras e renda, promoveu a exclusão de lavradores e aprofundou a desigualdade do desenvolvimento entre as regiões brasileiras. Investigações para avaliar o desenvolvimento agrário brasileiro revelaram que, mesmo ocorrendo aplicação de esforços e recursos públicos, grande parte da população rural permaneceu excluída dos supostos benefícios. Além desses resultados socioeconômicos mais evidentes, as análises sobre os impactos da modernização da agricultura brasileira realizadas por pesquisadores e movimentos sociais rurais têm revelado consequências ambientais nocivas para o solo, para a biodiversidade, para o estoque de água doce disponível e uma série de resultados deletérios derivados para as comunidades humanas.

Para Daniel Hogan, a articulação entre grupos sociais e natureza era fenômeno complexo que se manifestava de várias formas em sociedades e períodos diferentes, combinando séries diversas e mais ou menos criativas de relações das pessoas, entre si e com a natureza, entre o rural e o urbano. Sociedades se constroem em ambientes e a cultura humana age sobre o meio físico-material, propiciando significados e usos dos seus elementos (HOGAN, 2000, 2005, 2007). Mas, se há utilização exagerada dos recursos e/ou expansão demográfica, esses elementos podem se combinar para romper situações estáveis, fazendo com que a sociedade se reorganize forçada pelo esgotamento ecológico. Essa ruptura faz com que as sociedades humanas criem novas formas, nem sempre harmônicas, de se relacionarem com o meio - ao contrário do que apontou Boserup (1987).

Foram muitas as perspectivas inovadoras que Hogan introduziu no grande campo de estudo da relação população e ambiente - noções de desenvolvimento, vulnerabilidade, risco e mudanças climáticas. Mas não foram só noções vanguardistas. Acima de tudo, como autor, ele sabia aliar novidades com tradições de análise, e suas sínteses sempre foram a junção crítica de conhecimentos consolidados com perspectivas extremamente inovadoras.

É por isso que, dez anos depois de seu falecimento, sua obra conserva grande atualidade. Daniel Hogan é referência em estudos sobre vulnerabilidade, saúde, mobilidade espacial, ambiente urbano, porque seus estudos "travaram" de forma original temas que costumam ser recorrentemente disciplinários, aferrados a determinadas áreas de conhecimentos e que pouco costumam solicitar conhecimentos adicionais. Sua obra acrescentou 
transitividade a temas costumeiramente fechados em si mesmo, oferecendo "alças" que permitiram o transbordo de temas, abrindo diálogos onde antes existia silêncio.

Foi levando essa curiosidade à prática que Hogan se tornou excelente orientador: passava aos estudantes seu sólido conhecimento, sua vasta carga de leitura, estimulando que, ancorados por uma bibliografia consistente, percorressem caminhos teóricos e práticos novos, que ele invariavelmente, de perto ou de longe, percorria junto, dosando sempre liberdade de pensamento com o rigor metodológico no tratamento dos dados.

Boa parte das trajetórias de seus orientados de mestrado e doutorado revela a influência do orientador. Nas temáticas de dissertações e teses: relacionando ambiente, vulnerabilidade e risco de forma pioneira; refletindo sobre água no rural e no urbano, quando pouco se pensava na crise hídrica; equacionando a complexa relação entre mudanças ambientais e migrações.

Mas a influência de Daniel Hogan se manifestou principalmente nos destinos. Boa parte dos orientados seguiu carreira de pesquisador, em universidades ou em centros de pesquisas. E, não por acaso, quase todos lidam com transversalidades, ao tentar entender dinâmicas populacionais e ambientais em diversas perspectivas e ao assentar essas reflexões, como Hogan fazia, em um "saber vivo", na academia, em sociedades científicas, nos órgãos de fomento de ciência e tecnologia, em áreas da pós-graduação e em organizações sociais.

"Pense globalmente e pesquise localmente". Com esta afirmação, Hogan sintetizou o que entendia por fazer a boa ciência. A partir do estoque de conhecimento anterior, conhecer realidades específicas para então alargar as possibilidades de conhecimento:

[...] subprodutos negativos (desmatamento, perda de solos, etc.) são mais facilmente reconhecidos, se não tão facilmente resolvidos. Mas relações harmoniosas entre homem e seu meio físico dependerão de como ele exerce o seu "controle". No seu "hubris", ele produziu acomodações mais doces a processos naturais, e isto deve ser o leme do futuro (HOGAN, 1991, p. 68).

O legado de Hogan não se resume a excelentes contribuições teóricas - o que já seria muito -, mas também uma postura de pesquisador cioso, curioso, generoso, sempre aberto a perspectivas que indicassem "lemes do futuro", que ouvissem as possibilidades onde se imaginava só existir silêncios.

\section{Referências}

BOSERUP, E. Evolução agrária e pressão demográfica. São Paulo: Hucitec/Polis, 1987.

CAMARGO, C. P. F. de; CARDOSO, F. H.; MAZZUCHELLI, F.; MOISÉS, J. A.; KOVARICK, L.; ALMEIDA, M. H. T. de; SINGER, P. I.; BRANT, V. C. São Paulo 1975: crescimento e pobreza. São Paulo: Loyola, 1976.

CÂNDIDO, A. Os parceiros do rio Bonito. São Paulo: Livraria Duas Cidades, 1975.

CASTALDI, C. A aparição do demônio no Catulé. São Paulo: Anhembi, 1957. 
DURHAM, E. A caminho da cidade: a vida rural e a migração para São Paulo. São Paulo: Perspectiva, 1973.

HARDIN, G. The tragedy of the commons. Science, v. 162, n. 3859, p. 1243-1248, Dec. 1968.

HOGAN, D. J. Cidades: usos e abusos. São Paulo: Brasiliense, 1978.

Crescimento demográfico e meio ambiente. Revista Brasileira de Estudos de População, Campinas, v. 8, n. 1/2, p. 61-70, jan./dez. 1991.

. População, pobreza e poluição em Cubatão, São Paulo. In: MARTINE, G. População, meio ambiente e desenvolvimento. Campinas: Editora da Unicamp, 1996.

. Mobilidade populacional e meio ambiente. Revista Brasileira de Estudos de População, Brasília, v. 15, n. 2, p. 83-92, 1998.

A relação entre população e ambiente: desafio para a demografia. In: TORRES, H.; COSTA, H. (org.). População e meio ambiente: debates e desafios. São Paulo: Editora Senac, 2000.

. Mobilidade populacional, sustentabilidade ambiental e vulnerabilidade social. Revista Brasileira de Estudos de População, São Paulo, v. 22, n. 2, p. 323-338, jul./dez. 2005.

. (org.). Dinâmica populacional e mudança ambiental: cenários para o desenvolvimento brasileiro. Campinas: Nepo/Unicamp, 2007.

LOPES, R. B. Desenvolvimento e migrações: uma abordagem histórico-estrutural. Novos Estudos Cebrap, São Paulo, v. 6, p. 125-143, 1973.

QUEIROZ, M. I. P. O campesinato brasileiro. São Paulo, Vozes/Edusp, 1973.

\title{
Sobre os autores
}

Flavia Maria Galizoni é antropóloga, doutora em Ciências Sociais pela Universidade Estadual de Campinas (Unicamp). Professora associada da Universidade Federal de Minas Gerais (UFMG).

Eduardo Magalhães Ribeiro é economista. Professor titular da Universidade Federal de Minas Gerais (UFMG).

\section{Endereço para correspondência}

\author{
Flavia Maria Galizoni \\ Universidade Federal de Minas Gerais \\ Avenida Universitária, 1000 \\ 39404-547 - Montes Claros-MG, Brasil \\ Eduardo Magalhães Ribeiro \\ Universidade Federal de Minas Gerais \\ Avenida Universitária, 1000 \\ 39404-547 - Montes Claros-MG, Brasil
}




\begin{abstract}
Listening to silences: Daniel Hogan, the rural world and nature

Daniel Hogan's (1942/2010) academic production and attitudes are still crucial to understand the relationship between population and environment in rural Brazil, especially with regard to great migrations, accelerated urbanization and their effects on the environment. These contributions appear in studies which have analyzed silences, and thus created innovative analytical perspectives that strengthened the ability to filter techniques in order to guide studies.
\end{abstract}

Keywords: Rural population. Environment. Migrations. Daniel Hogan.

\title{
Resumen
}

Oyendo silencios: Daniel Hogan, el mundo rural y la naturaleza

La producción y las actitudes de Daniel Hogan (1942-2010) siguen siendo fundamentales para comprender las relaciones entre población y ambiente en el medio rural brasileño, especialmente en lo que se refiere a las grandes migraciones, a la urbanización acelerada y a sus efectos sobre el medio. Esas contribuciones aparecen en estudios que investigaron silencios - grandes lagunas que, hasta entonces, había en la literatura-, y que crearon así perspectivas analíticas innovadoras que fortalecieron la capacidad de filtrar técnicas para orientar estudios.

Palabras clave: Población rural. Medio ambiente. Migraciones. Daniel Hogan.

Recebido para publicação em 23/11/2018

Aceito para publicação em 03/05/2019 